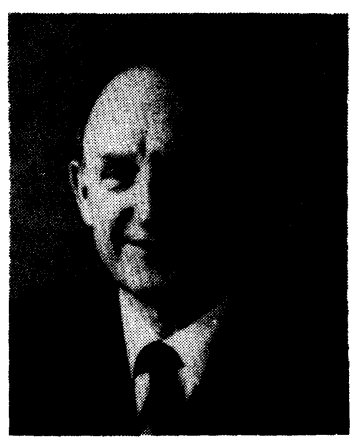

\section{An Interim Report}

I am writing this editorial immediately after speaking with our managing editor to make sure that the June issue has been "put to bed." It is, and we can now work on the July issue and subsequent issues. The June issue has 184 pages, which will bring the total number of pages published in the first six months of the year to 856 . This puts us $5 \%$ ahead of last year and ahead of each of the last five years. I cannot take too much credit for that since the majority of these papers are ones processed by Jack Gaskill, our former editor, but I believe we have streamlined our method for processing papers once they have been accepted and sent to Bellingham.

The quality and the content of our journal is determined initially by the quality of the submitted papers, both for the regular issues and the specials. Our quality control is, of course, the review process, with each paper being sent to at least two independent reviewers. As editor, I take care of the processing of all the general submission papers. The guest editors process the papers submitted for their specialswhich includes selecting the reviewers. Once a paper is reviewed, the guest editor will either accept or reject that paper and send the accepted papers on to me for a final check and formal acceptance for publication.

So far this year (through the end of May), we have received 94 papers that were submitted directly to the editor. This total does not include the submissions for the special issues. As of the end of May, the general submissions are $35 \%$ ahead of last year. We hope that this trend continues.
This editorial office started to receive papers as of the first of December 1990. In December, we received eleven papers; of those one was accepted outright, five were accepted after some revisions, two are with the authors for revision, one was rejected but can be resubmitted, and two were rejected. The January statistics are: four papers accepted after some revision, five papers are with the authors for revision, three were rejected but can be resubmitted, and five were rejected. Two papers are still out for review.

At the present time, based on the above two months, it is taking an average of 12 weeks from date of receipt of a paper to the date of my letter to the author about the outcome of the review. For those papers that have completed the cycle to final acceptance or rejection, the average time from original date of receipt of the manuscript is $\mathbf{1 5 . 5}$ weeks. Since some papers are still out with the authors for revision, that average time could increase somewhat.

Stay in touch with these editorials for further information and statistics. If you are asked to review a paper, please accept and get your review back promptly. If you are an author, please submit your paper to Optical Engineering and get any revisions to your manuscript back to the editor as soon as possible.

Brian J. Thompson Editor 


\section{August 1991}

\section{X-Ray/EUV Optics}

Richard Hoover

NASA-Marshall Space Flight Center

Space Science Laboratory, ES-52

Huntsville, AL 35812

205/544-7617

\section{November 1991}

\section{Infrared Imaging Systems}

Mohammad A. Karim

University of Dayton

Center for Electro-Optics

Dept. of Electrical Engineering

300 College Park Ave.

Dayton, OH 45469-0226

$513 / 229-3611$

\section{January 1992}

\section{Smart Materials and Structures}

Richard O. Claus

Virginia Polytechnic Institute and State University

Dept. of Electrical Engineering

Fiber and Electro-Optics Research Center 648 Whittemore Hall

Blacksburg, VA 24061

$703 / 231-4580$

\section{March 1992}

\section{Optics in Poland}

Romuald Jozwicki

Warsaw Institute of Technology

Institute of Design of Precision and

Optical Instruments

ul. Chodkiewicza 8

02-525 Warsaw, Poland

\section{April 1992}

Optical Methods and Means of Information Processing

Mikhail M. Miroshnikov

S.I. Vavilov State Optical Institute

199034, Birjevaya Liniya 12

Leningrad, USSR

\section{May 1992}

Optical Implementation of Information Processing, Pattern Recognition, and

\section{Neural Networks}

Bahram Javidi

University of Connecticut

Department of Electrical and Systems

Engineering

Room 312, U-157

260 Glenbrook Road

Storrs, CT 06269-3157

203/486-2867

203/486-0318 FAX

This special issue will cover the following areas: optical information processing, including linear and nonlinear operations and transforms; pattern recognition, correlation, filters, distortion invariant object identification; applications of holography in information processing; feature extraction and classification; associativeprocessors and neural networks; and applications of spatial light modulators inone- and two-dimensional information processing.

Authors are invited to submit manuscripts on any of the above topics for inclusion in the special issue. Manuscripts should be sent to Bahram Javidi before August 1, 1991.

\section{June 1992}

\section{Adaptive Signal Processing}

Simon Haykin

McMaster University

Communications Research Laboratory

1280 Main Street West

Hamilton, Ontario L8S 4K1 Canada 416/525-9140

This special issue will cover the following areas: historical perspective of adaptive signal processing, fast algorithms for adaptive filtering, blind deconvolution, chaotic models, wavelet transforms, and neural networks. The emphasis will be on theory and applications.

\section{August 1992}

Optical Engineering and U.K. Industry

Lionel R. Baker

Sira Ltd.

South Hill, Chislehurst

Kent BR7 5EH, United Kingdom

+44814672636

+4481467 6515 FAX

\section{R. J. Parker}

Rolls Royce plc

P.O. Box 31

Derby DE2 8BJ, United Kingdom

This special issue will represent a typical cross section of current applied research taking place in the United Kingdom in the field of optics. We invite those who would like to submit manuscripts to notify $L$. $R$. Baker of the title and principal author as soon as possible. Those papers that receive provisional acceptance will begin the refereeing process in early September 1991

We regard this as an excellent opportunity to promote the best in U.K. optics research worldwide and sincerely hope you will be among those able to offer a title for consideration by our Papers Committee.

\section{January 1993}

\section{Optical Research in Asia}

Chung J. Kuo

National Chung Cheng University Department of Electrical Engineering Chiayi, Taiwan 62107

886-5-226-3410, ext. 6210

886-5-226-3435 FAX

Toshimitsu Asakura

Hokkaido University

Research Institute of Applied Electricity

N12, W6 Sapporo

Hokkaido, 060 Japan

81-11-716-2111

This special issue will present innovative research and development results from Asian countries. Every field of photonics will be considered. Prospective authors are invited to submit manuscripts for consideration. Manuscripts should be received by Chung J. Kuo or Toshimitsu Asakura before Feb. 1, 1992. 